\title{
OS DIREITOS SOCIAIS NA JURISPRUDÊNCIA CONSTITUCIONAL ITALIANA*
}

\author{
STEFANO MARIA CICCONETTI ${ }^{* *}$
}

\begin{abstract}
RESUMO: O presente texto aborda inicialmente a questão da concretização dos direitos fundamentais sociais no ordenamento italiano, tratando brevemente de questões tópicas, como a eficácia dos direitos prestacionais. Logo após, empreende discussão mais detalhada dos aspectos principais da proteção do direito ao trabalho na Itália, entre eles o da garantia de não-discriminação e o das férias. Por fim, discute ainda, brevemente, questões relacionadas aos direitos à moradia, à saúde e à educação.

PALAVRAS-CHAVE: Direitos Sociais, Itália, Concretização, Direito ao Trabalho.
\end{abstract}

ABSTRACT: The present text deals initially with the question of the realization of fundamental social rights in the Italian legal order, briefly touching topic issues, such as the efficacy of serviceable rights. Next, it discusses in a more detailed fashion the main aspects of the protection of the right to labor in Italy, especially that of the warranty of non-discrimination and that of vacations. Finally, it faces, however swiftly, matters related with the rights to housing, health and education.

KEYWORDS: Social Rights, Italy, Realization, Right to Labor.

SUMÁRIO: 1. Os direitos sociais na Constituição italiana. 2. Os direitos inerentes ao mundo do trabalho. 3 . $\mathrm{O}$ direito à habitação. 4 . $\mathrm{O}$ direito à saùde. 5 . $\mathrm{O}$ direito ao estudo.

\section{OS DIREITOS SOCIAIS NA CONSTITUIÇÃO ITALIANA}

Os direitos sociais são tradicionalmente definidos como "direitos a prestações positivas por parte do Estado ou de entes públicos" (ex: direito ao trabalho, direito dos índios a tratamento médico gratuito, direito à assistência e à previdência sociais, etc.), os quais, diferentemente dos direitos de liberdade, requerem para a sua realização a prévia intervenção legislativa e administrativa. Todavia, esta definição pode gerar alguns equívocos, seja porque todos os direitos, ainda aqueles de liberdade, dependem na realidade da organização do Estado (caso o poder judiciário não estivesse préconstituido como poder distinto do poder político, que sentido teria falar de tutela da liberdade pessoal?), seja porque também os direitos "sociais” têm um “conteúdo mínimo", que é de qualquer forma protegido pela Constituição, mesmo quando o Estado não tenha organizado a sua "prestação". A partir destas bases, alguns constitucionalistas

* Tradução de Anderson V. Teixeira. Doutorando em Filosofia do Direito pela Universidade de Florença. Mestre em Direito do Estado pela PUCRS. Professor universitário e advogado.

** Professor Catedrático da Universitá Degli Studi; Professor Titular de Direito Constitucional e Direito Parlamentar da Università Roma Tre; Pós-Doutor pelas Universidades de Estocolmo, Viena e Berlim. 
entendem que não existe uma diferença estrutural entre os direitos sociais e os direitos de liberdade ou que, como veremos, seja preferível distinguir, no âmbito dos direitos exclusivamente definitos como sociais, os direitos condicionados, cujo gozo pressupõe uma organização idônea à satisfação da prestação, dos direitos incondicionados, que, por sua estrutura, seriam semelhantes aos direitos de liberdade, no sentido que se realizam independentemente de qualquer mediação legislativa (ex: a liberdade de escolha de uma profissão, a liberdade de instituir e gerir escolas, o direito de greve, etc.).

Muitas disposições constitucionais em tema de direitos sociais remetem à atividade sucessiva dos poderes públicos: por exemplo, com referência à manutenção e à educação dos filhos, o art. 30, § $2^{\circ}$, da Constituição, estabelece que "nos casos de incapacidade dos pais, a lei exige que os mesmos sejam isentados dos seus trabalhos"; ou, ainda, o art. 31 prevê que “a República facilita através de medidas econômicas e outras providências a formação da família...”

Durante anos foi discustido na Itália se disposições como estas seriam minimante “justificáveis”, se elas poderiam, em outras palavras, constituir o fundamento de uma ação frente ao juiz para obter a prestação prevista na Constituição. Inicialmente, prevaleceu a tese da sua natureza "programática”, a qual induzia a considerá-las como normas desprovidas de direta aplicabilidade, meros programas exigíveis somente do ponto de vista político. Mas, posteriormente, graças à decisiva contribuição da jurisprudência constitucional (desde a primeira Sentença, $\mathrm{n}^{\circ} 1$ de 1956), também as referidas disposições programáticas revelaram um conteúdo prescritivo, fundamentando direitos imediatamente acionáveis pelo seu titular ou, mais freqüentemente, determinando declarações de inconstitucionalidade de disposições legislativas que não garantiam adequadamente $o$ direito tomado em consideração. A Corte constitucional italiana recorreu, nestes casos, à sentenças "aditivas", que se resolvem na declaração de inconstitucionalidade de uma omissão legislativa (a disposição impugnada é inconstitucional "na parte em que não prevê $x$ ”) ou ainda à sentenças "substitutivas" (a disposição impugnada é inconstitucional "na parte em que prevê $x$ ao invés de y”). Pense-se na Sentença $\mathrm{n}^{\circ} 215$ de 1987, a qual tinha por objeto a disciplina legislativa relativa ao inserimento escolar dos portadores de deficiências, e, mais precisamente, uma disposição da Lei $n^{\circ} 118$ de 1971 (art. 28, § 3º), a qual prevê que "será facilitada ... a freqüência dos civis invalidos e mutilados às escolas de ensino médio, superior e universitária”. A Corte constitucional declarou ilegítima esta disposição na parte em que, com referência aos indivíduos portadores de handicap, prevê que "será facilitada", ao invés de dispor que "é assegurada” a freqüência nas escolas médias e superiores. Na motivação da sentenza se lê que "a disposição impugnada possui indubitavelmente um conteúdo exclusivamente programatório, limitando-se a exprimir somente um genérico empenho e uma simples remissão à imprecisas e futuras facilitações. O seu teor não é portanto apto a conferir certeza à condição jurídica dos portadores de deficiência”. Para realizar este objetivo a Corte é "constringida" a "transformar" a disposição impugnada de tal modo que esta adquira um valor "imediatamente prescritivo e cogente", prevendo que a freqüência escolar "é assegurada” ao invés de "será facilitada”.

Mais em geral, da jurisprudência constitucional emerge a tendência em considerar os direitos de "prestação” como sujeitos a um necessário contra-balanceamento com 
exigências de ordem organizativa e, sobretudo, de finanças públicas. Disto decorre a possibilidade para os poderes públicos graduarem as prestações com base nas suas disponibilidades financeiras, mas não para comprimir as mesmas até o ponto em que determinem o total sacrifício do direito social que se discute (ver, entre muitas, Corte const., sentença $\mathrm{n}^{\circ} 260$ de 1990). Muito freqüentemente, com referência à eficácia dos direitos sociais, a valutação realizada pela Corte se traduz em uma análise sobre a razoabilidade da escolha legislativa, sobre a não arbitrariedade do contra-balanceamento operado pelo legislador, o qual, "medindo as efetivas disponibilidades e os interesses que a partir destas são gradualmente realizáveis, pode racionalmente tratar de reportar meios a fins, e construir pontuais fatispecie expressivos justificáveis de tais direitos fundamentais” (Corte const., sentenças nº 252 de 1989 e nº 121 de 1996).

Como se disse, uma parte da doutrina, ainda com base em algumas orientações produzidas na jurisprudência constitucional, tende, mais que a distinguir genericamente os direitos sociais dos direitos de liberdade, mas sim a subdividir os direitos sociais em originários (ou incondicionados) e em derivados (ou condicionados): os primeiros atendem a relações jurídicas que se instituem a partir da livre iniciativa das partes, a fim de qualificar o tipo ou a quantidade de tais prestações (ex: o direito à retribuição proporcional e suficiente); os segundos são direitos cujo gozo depende da existência de uma organização necéssaria e apta a dar efetividade à prestação objeto dos direitos em discussão (ex: o direito à assistência e à Previdência Social). Enquanto os direitos originários (ou incondicionados) podem ser feitos valer diretamente dos titulares do direito quando em conflito com a parte contrário, sendo pedido ao juiz que estabeleça o quantum da prestação, quando este não seja já pré-determinado pelo legislador, aqueles derivados (ou condicionados) são direitos que pressupõem uma atuação legislativa.

Além de tais classificações, a categoria dos direitos sociais previstos pela Constituição italiana compreende também os direitos inerentes ao mundo do trabalho (arts. 4, 35, 36, 37, 38 e 40 da Constituição), o direito à habitação, o direito à saúde (art. 32 da Constituição), e, enfim, o direito ao estudo (art. 34 da Constituição).

Ao proceder un rápido excursus sobre os direitos sociais, como acima feito, não me restringirei, por razões de tempo, sobre a eficácia legislativa das disposições constitucionais, dando sobretudo relevo aos principais orientamentos surgidos na jurisprudência constitucional.

\section{OS DIREITOS INERENTES AO MUNDO DO TRABALHO}

A Constituição italiana prevê no art. $4^{\circ}, \S 1^{\circ}$, que “A República reconhece a todos os cidadãos o direito ao trabalho e estimula as condições que tornem efetivo este direito". Segundo o afirmado pela Corte constitucional na Sentença $n^{\circ} 45$ de 1965, “a partir do contexto geral do primeiro parágrafo do art. $4^{\circ}$ da Constituição (...) se depreende que o direito ao trabalho, reconhecido a cada cidadão, é de se considerar um tão fundamental direito de liberdade da pessoa humana, que se externaliza através da escolha e do modo de exercício da atividade laboral. A esta situação jurídica do cidadão - a única que encontra na norma constitucional em exame o seu inderrogável fundamento - faz com que, naquilo que concerne ao Estado, dê-se por um lado a proibição de criar ou de deixar subsistir no ordenamento normas que ponham ou permitam pôr limites discriminatórios a tal liberdade, mesmo que diretamente ou 
indiretamente a reneguem, e por outro lado cria a obrigação - cujo cumprimento é considerado pela Constituição como essencial à efetiva realização do referido direito - de endereçar a atividade de todos os poderes públicos, e do próprio legislador, à criação de condições econômicas, sociais e jurídicas que possibilitem o emprego a todos os cidadãos em condições de trabalhar”.

Se - como emerge também da sucessiva jurisprudência constitucional (veja, por exemplo, Sentenças n ${ }^{\text {os }} 2$ e 270 de 1986, 238 de 1988) - do art. $4^{\circ}$ da Constuição não se pode deduzir o reconhecimento às pessoas desprovidas de ocupação uma efetiva pretensão de acesso ao trabalho, disto se deduz de qualquer forma o direito à livre escolha da atividade laboral, a qual compreende antes de tudo a liberdade de acesso ao trabalho, que se traduz na proibição de irrazoáveis limitações ao ingresso na profissão pré-escolhida. Porém, deve se recordar que o trabalho é configurado pela nossa Constituição também como um "dever” ao cidadão “de desenvolver, segundo as próprias possibilidades e a própria escolha, uma atividade ou uma função que concorra ao progresso material ou espiritual da sociedade” (art. $4^{\circ}$, § $2^{\circ}$, da Constituição).

Com o fim de tornar efetiva a liberdade de acesso ao trabalho, a Corte constitucional italiana removeu significativas limitações legislativas ao ingresso na profissão pré-escolhida, mantendo-as em contraste com o art. $4^{\circ}$, ainda que, em alguns casos, com as disposições constitucionais destinadas a proteção da maternidade e da família (arts. 29, 30 e 31 da Constuição). Assim, na Sentença $n^{0} 332$ de 2000, a Corte declarou a inconstitucionalidade de uma disposição contida na Lei n ${ }^{\circ} 64$ de 1942 (art. 7º, alínea 3) "na parte em que inclui, entre os requisitos necessários para ser recrutado pelo Corpo da Guarda de finanças, estar sem prole”. Uma limitação tão grave, como a prevista pela disposição censurada, de fundamentais direitos da pessoa, quais sejam, o de procriar e se tornar pai ou mãe, não poderia de fato ser entendida como justificada pela intensidade e exigência de uma exclusividade da relação de dedição que deve ligar o militar em fase de instrução ao corpo de afiliação profissional, devendo a necessária continuidade na freqüência dos cursos de treinamento encontrar garantias em regras e procedimentos diferentes da proibição de possuir prole.

Nesta mesma perspectiva, merece ser mencionada a Sentença $n^{\circ} 445$ de 2002, na qual a Corte constitucional entendeu que a ausência de vínculo conjugal não pode ser requisito legítimo para o acesso aos cargos públicos, de modo que tal imposição se traduziria, indiretamente, em uma limitação ao exercício de direitos fundamentais, como o direito a contrair casamento (reconhecido como direito inviolável na Sentença $n^{\circ} 27$ de 1969) e o direito a não ser submetido a interferências arbitrárias na vida privada.

Analogamente, pode-se recordar a Sentença no 108 de 1994, na qual foi declarada inconstitucional uma disposição, contida na Lei no 53 de 1989 (art. 26), que para o acesso às carreiras de polícia do Estado requeria que o interessado fizesse parte de família de conduta moral ilibada. A Corte entendeu que tal condição não pode se constituir em um requisito razoável ao ingresso nas carreiras de polícia do Estado, já que não concerne à capacidade, comportamenteo ou condutas relativas ao aspirante, mas sim juízos ou comportamentos imputáveis aos seus familiares, sendo que tais juízos - com base em uma presunção legislativa arbitrária, não mais correspondente à situação social italiana - são automaticamente imputados ao sujeito interessado; a 
previsão do referido requisito se transforma portanto em uma irrazoável e discriminatória limitação da possibilidade de acesso aos cargos públicos, além do que a definição quanto à falta de tais requisitos morais não é restrita à avaliações imparciais, baseadas sobre fatos específicos e determinadas através da motivação do procedimento de modo a possibilitar o controle de legitimidade do julgador administrativo -, mas, pelo contrário, é agora remetido à avaliação indelegável do Ministro, com base nas “informações recolhidas” pelos aparatos administrativos ou pelas repartições da polícia de Estado.

Todavia, ainda que a liberdade de accesso ao trabalho possa encontrar restrições, no contra-balanceamento com outros interesses constitucionais, bem podendo, por exemplo, o legislador fixar requisitos de adequada preparação necessários ao exercício de uma determinada atividade profissional em vista da tutela da coletividade ou dos interessados (Sentença $n^{\circ} 441$ de 2000). O legislador, na sua discricionariedade, pode, em outras palavras estabelecer restrições na disciplina do acesso ao trabalho (determinação de requisitos particulares, determinação de modos e condições para a contratação, etc...), “com o óbvio limite da total supressão ou da grave lesão ao direito de liberdade dos indivíduos, entre as quais a livre escolha da atividade de trabalho" (sentença $\mathrm{n}^{\circ} 248$ de 1986).

O reconhecimento do direito ao trabalho, estabelecido no art. $4^{\circ}$, se vincula a outras previsões contidas no Título III da Parte I da Constituição italiana. Ocorre, antes de tudo, relembrar o art. 35 da Constituição, na parte em que prevê que "A República tutela o trabalho em todas as suas formas e aplicações", protegendo, em particular, "a formação e a qualificação profissional dos trabalhadores". Esta previsão, conforme o afirmado pela Corte constitucional, possui uma "função introdutória” no que concerne às sucessivas disposições contidas no Título III da Parte I da Constituição, as quais dizem respeito, principalmente, ao trabalho subordinado. Em particular, o sucessivo art. 36 da Constituição reconhece os mais importantes direitos sociais inerentes à relação de trabalho, estabelecendo: a) que “o trabalhador tem direito a uma retribuição proporcional à quantidade e qualidade do seu trabalho e em cada caso suficiente para assegurar a si e a sua família uma existência livre e digna” (parágrafo 1); b) que “a duração máxima da jornada laboral será estabelecida pela lei” (parágrafo 2); c) que "o trabalhador tem direito ao repouso semanal e a férias anuais remuneradas, e não pode disto renunciar” (parágrafo 3).

A remuneração, para ser justa, deve ser proporcional e suficiente, não "mero correspectivo do trabalho, mas remunerando o trabalho, proporcionalmente na sua quantidade e qualidade, sendo, juntamente, meio normalmente exclusivo para suprir às necessidades vitais do trabalhador e dos seus familiares", devendo "ser suficiente para assegurar àqueles uma existência livre e digna” (Corte constitucional, Sentença $\mathrm{n}^{\circ} 559$ de 1987). Com a finalidade de determinar a remuneração, a jurisprudência entendeu que os acordos coletivos de direito comum, que por si deveriam valer somente para os trabalhadores que pertencem a sindicatos que assinaram tais acordos, podem valer também para os não inscritos para a individualização do tratamento mínimo inderrogável dos contratos individuais. De outra sorte, como recentemente se viu afirmado pela Corte de Cassação, quando não for possível fazer referência a um acordo coletivo 
estipulado para a específica categoria a qual pertence a empresa, o juiz pode individualizar uma categoria afim, sem estar vinculado pela indicação das partes (Cass., sez. lav., 17 marzo 2000, n ${ }^{\circ}$ 3184). O art. 36, § $1^{\circ}$, da Constituição mostra assim a sua "imediata prescritividade", podendo o juiz declarar a nulidade das cláusulas retributivas dos contratos individuais contrastantes com os princípios lá expressos, e fixar a remuneração segundo eqüidade, nos termos do art. 2099, § $2^{\circ}$, do Código Civil.

Ainda no que diz respeito à determinação da prestação laboral (duração dos descansos diários e repousos semanais e anuais), têm ocorrido importantes atuações da jurisprudência que merecem ser recordadas. Penso, antes de tudo, em relação à declaração de inconstitucionalidade do art. 2109 do c.c. que coloca o decurso de um ano de ininterrupto serviço como pressuposto do direito do trabalhador a um período de férias anuais retributivas (Sentença $n^{\circ} 66$ de 1963). A Corte salienta, no caso, que o art. 36 da Constituição determina que as férias sejam gozadas dentro de um ano e não após um ano de trabalho (como diferentemente prescreve o código). Pelas mesmas razões será em seguida declarado ilegítimo o art. 2243 do c.c., limitadamente ao inciso “depois de um ano de ininterrupto serviço”, enquanto que introduz um limite ao direito às férias do trabalhador doméstico não permitido inicialmente pela citada norma constitucional (Sentença $n^{0} 16$ de 1969). O direito do trabalhador às férias anuais satisfaz ao objetivo de proteger as energias psicofísicas, o que implica, entre outras, na suspensão do decurso do período de férias em caso de doença sobrevinda do trabalhador (Sentença $n^{\circ} 616$ de 1987). A garantia do repouso (diário, anual e semanal) vale para assegurar a satisfação das exigências básicas do trabalhador, entre as quais, como recém dito, a recomposição deas energias psicofísicas, e não poder ser negada nem mesmo a quem preste atividade laboral em estado de detenção. Sobre este ponto deve, sem dúvidas, ser mencionada a Sentença $n^{\circ} 158$ de 2001, com a qual foi declarado constitucionalmente ilegítimo o art. 20, § 17, da Lei $n^{\circ} 354$ de julho de 1975 (Código penitenciário), na parte em que não reconhecia o direito ao repouso anual retribuído ao preso que preste a própria atividade laboral nas dependências da administração carcerária. A garantia do repouso anual - imposta em qualquer relação de trabalho subordinado, por explícita vontade do Constituinte - não autoriza derrogações e faz, deste modo, que ela seja assegurada a cada trabalhador, sem distinções de qualquer sorte, (veja-se Sentenças n ${ }^{\text {os }} 76$ de 1962, 189 de 1980, 40 de 1981, 452 de 1991), portanto - ressalta ainda a Corte - mesmo ao preso, seja que com diferenciações de modalidade.

O princípio de não discriminação na relação de trabalho encontra uma particular tradução na Constituição italiana no que tange às mulheres e aos menores (art. 37). Uma significativa ação legislativa e jurisprudencial foi realizada, ainda que tardiamente, no que diz respeito à tutela das mães que trabalham, de modo a permitir à mulher, segundo o determinado pela Constituição, "a realização da sua função essencial familiar e assegurar à mãe e à criança uma especial e adequada proteção” (art. 37, § 1º, da Constituição). Naquilo que diz respeito à jurisprudência constitucional, vale recordar, antes de tudo, a Sentença $n^{\circ} 270$ de 1999, na qual, sob o pressuposto que a abstenção obrigatória do trabalho no caso de maternidade é destinada a tutelar a mãe, a criança e a relação que entre ambos se instaura, foi declarada a inconstitucionalidade de uma 
disposição contida na lei que trata da "Tutela das mães que trabalham” (art. $4^{\circ}, \S 1^{\text {o }}$, alínea $c$, da Lei ${ }^{\circ} 1204$ de 1971), na parte em que não prevê para a hipótese de parto prematuro uma decorrência dos prazos do período da abstensão obrigatória capaz de assegurar uma adequada tutela da mãe e da criança. No mesmo sentido, pode-se recordar, entre outras, a Sentença $\mathrm{n}^{\circ} 360$ de 2000, com a qual foi declarada a ilegitimidade constitucional do art. $1^{\circ}$, § $2^{\circ}$, da Lei $n^{\circ} 1204$ de 1971 , na parte em que não prevê a aplicabilidade às trabalhadores à domicílio do art. $5^{\circ}$ da referida lei, a qual disciplina a abstensão do trabalho por parte da trabalhadoras em estado de gravidez.

Neste rápido excursus sobre os direitos sociais inerentes ao mundo do trabalho, deve-se ainda analisar as prescrições contidas no art. 38 da Constituição, que concernem situações diferentes: o primeiro parágrafo estabelece que "cada cidadão inapto ao trabalho e desprovido dos meios necessários para viver tem direito à manutenção da vida e à assistência social”; o segundo parágrafo prevê que "os trabalhadores têm direito que sejam previtos e assegurados meios adequados as suas exigências de vida em caso de infortúnio, doença, invalidez e senilidade, desocupação involuntária”. O primeiro parágrafo, o qual se refere aos sujeitos desprovidos de capacidade para o trabalho e que se encontram em estado de necessidade, garante aos mesmos a assistência social, incumbindo aos devidos aparatos públicos a obrigação de produzir prestações destinadas a prover os meios necessários para viver. O segundo parágrafo, o qual se refere a quem exercita ou tenha exercitado uma atividade laboral, garante ao mesmo a Previdência Social, incumbindo aos devidos aparatos públicos a obrigação de produzir prestações destinadas a prover os meios necessários para viver, com base, mas não exclusivamente, nas contribuições produzidas durante os períodos de trabalho deste indivíduo (veja-se Sentença $n^{\circ} 31$ de 1986). Todavia, não obstante venha reconhecida a natureza prescritiva do art. 38 da Constituição, a realização do mesmo termina por depender das disponibilidades do orçamento público, o qual o legislador deve levar em conta na disciplina das prestações previdenciárias e assistenciais.

Cabe examinar, por último, com referência aos direitos inerentes ao mundo do trabalho, o direito de greve, o qual, nos termos do art. 40 da Constituição, "se exercita no âmbito das leis que o regulam”. A greve vem se configurando como direito individual de exercício coletivo, utilizável não somente com finalidades econômicas, mas também, em última instâncias, políticas, sempre que não seja destinado à subversão da ordem constitucional ou a obstaculizar o normal desenvolvimento das funções dos órgãos representativos (Corte constitucional, Sentença $n^{\circ} 270$ de 1974). Não obstante a Constituição remeta à lei a tarefa de regulamentar o direito de greve, durante longo tempo, na ausência de uma disciplina, os limites ao seu exercício têm sido, freqüentemente, determinados pelos juízes. Os problemas maiores têm ocorrido no exercício da greve nos serviços públicos essenciais (ex: transportes e saúde), na ausência de limites expressos para garantir as prestações mínimas indispensáveis à tutela de tais direitos da pessoa, constitucionalmente tutelados - quais sejam, por exemplo, vida, saúde, liberdade e segurança - que, mesmo em ocasião de uma greve, devem ser assegurados. Sobre este ponto foi finalmente feita a Lei $n^{\circ} 146$ de 1990 (posteriormente reformada pela Lei $\mathrm{n}^{\circ} 83$ de 2000), a qual prevê um envolvimento dos sindicatos na definição das próprias prestações mínimas e determina que um prazo 
de pré-aviso seja estabelecido para permitir uma adequada informação a todos os usuários dos serviços públicos. Exatamente com a finalidade de proteger interesses constitucionalmente tutelados envolvidos por fenômenos de abstensão coletiva do trabalho, a Corte constitucional extendeu as disposições da Lei n ${ }^{\circ} 146$ de 1990 a situações que não parecem se enquadrar na tutela do art. 40 da Constituição. Assim, na Sentença $n^{\circ} 171$ de 1996, a Corte declarou a inconstitucionalidade do art. $2^{\circ}$, $\S \S 1^{\circ}$ e $5^{\circ}$, da Lei $n^{\circ} 146$ de 1990, na parte em que não prevê, no caso de abstensão coletiva da atividade judiciária por parte dos advogados, a obrigação de um coerente pré-aviso e de um razoável limite temporal à abstensão e não estabelece quais são os instrumentos aptos a individualizar e a assegurar as prestações essenciais, nem sequer os procedimentos e as medidas decorrentes da hipótese de sua inobservância. Se é verdade que a abstensão ao trabalho por parte dos advogados, estando determinada a condição de independência dos mesmos, não se enquadra na proteção do art. 40 da Constituição, todavia afirma a Corte - o objetivo da Lei $n^{\circ} 146$ é a garantia dos serviços públicos essenciais que não pode ser prejudicada por manifestações coletivas capazes de ameaçar os valores básicos da pessoa, no caso os direitos fundamentais dos sujeitos que, em diversos modos, são destinatários da função jurisdicional. Segundo a Corte, a falha previsão de abstensão às audiências por parte dos advogados entre aquelas que a Lei $n^{\circ} 146$ arrola, compromete suas finalidades e reduz sua eficácia, de modo que tal abstensão incide, em medida não inferior que a da greve do pessoal técnico-administrativo das secretarias judiciárias, sobre a administração da justiça, a qual é serviço público essencial.

\section{O DIREITO À HABITAÇÃO}

Ainda que não seja expressamente previsto na Constituição italiana, parece que deva ser compreendido entre os direitos sociais também o direito à habitação, o qual "constitui, devido a sua fundamental importância na vida do indivíduo, um bem primário [que] deve ser adequadamente e concretamente tutelado pela lei” (Corte constitucional, Sentença $n^{\circ} 404$ de 1988). Todavia, não existindo um monopólio público do mercado das habitações, que entretanto contrastaria com específicas disposições constitucionais (arts. 41 e 42 da Constituição), o direito à habitação não foi entendido, na jurisprudência constitucional, como direito a receber uma propriedade, um imóvel em locação ou um alojamento de qualquer sorte, nem como direito subjetivo do locatário à estabilidade de gozo do próprio imóvel alugado. O direito à habitação tem sido entendido em uma outra acepção, definida "frágil”, como pretensão que tem por objeto a conquista da disponibilidade de um local para morar, a qual os entes públicos são chamados a realizar (Sentenças n ${ }^{\text {os }} 49$ de 1987, 399 e 599 de 1989, 142 e 491 de 1991, 169 de 1994).

A Corte constitucional reconheceu, em particular, o direito à habitação do convivente more uxorio, uma vez que se trata de direito inviolável da pessoa, destinado a garantir uma vida digna para si e para os eventuais filhos (Sentença $n^{\circ} 404$ de 1988), assim como a legitimidade da adoção, nas áreas de alta tensão habitacional, de uma legislação que promova a aquisição da primeira habitação em favor dos jovens trabalhadores subordinados, no sentido de conferir o máximo de efetividade a um direito social fundamental destinado a assegurar condições mínimas de subsistência 
(Sentença $n^{\circ} 217$ de 1988). Precisamente nesta última decisão, a Corte salientou que "o direito à habitação entra entre os requisitos caracterizantes da dimensão social a que se conforma o Estado democrático desejado pela Constituição” e que o Estado não pode em nenhum caso abdicar à tarefa de "agir no sentido de garantir ao maior número possível de cidadãos um fundamental direito social como propriamente o direito à habitação", contribuindo "para que a vida de cada pessoa reflita todos os dias e sob qualquer circunstância a imagem universal da dignidade humana”.

De qualquer forma, o direito à habitação "como qualquer outro direito social ... é direito que tende a ser realizado nas proporções dos recursos da coletividade; somente o legislador, medindo as efetivas disponibilidades e os interesses com estas gradualmente realizáveis, pode racionalmente encontrar os meios que chegam aos fins, e construir pontuais fatispecies que dêem a justa espressão a tais direitos fundamentais" (Sentenças n ${ }^{\text {os }} 252$ de 1989 e 121 de 1996).

\section{O DIREITO À SAÚDE}

A Constituição italiana define a saúde como "fundamental direito do indivíduo" e como "interesse da coletividade” (art. 32, $1^{\circ}$ parágrafo). O bem da saúde é portanto tutelado "não só como interesse da coletividade, mas também e sobretudo como direito fundamental do indivíduo” (Sentença $n^{\circ} 356$ de 1991), que requer plena e exaustiva tutela (Sentenças $n^{\circ} 307$ e $n^{\circ} 455$ de 1990), enquanto “direito primário e absoluto, plenamente operante também nas relações entre privados” (Sentenças n ${ }^{\text {s }} 88$ de 1979, 184 de 1986, 559 de 1987, 202 de 1991).

O "estado de saúde" - como sublinhado pela Corte constitucional - não se exaure só em situações ativas de pretensão, mas "implica e compreende o dever de não lesar nem pôr em risco com o próprio comportamento a saúde de outrem” (Sentença $\mathrm{n}^{\circ} 218$ de 1994). Nesta perspectiva, se justifica a possibilidade de imposições de tratamentos sanitários obrigatórios (tratamentos relativos a doenças contagiosas e infecciosas, vacinações obrigatórias, etc.), a qual deve ser disposta em lei e não pode em nenhum caso violar os limites impostos pelo princípio do respeito à pessoa humana (art. 32, $\S 2^{\circ}$, da Constituição). Como precisado pela Corte constitucional, a “imposição legislativa de um tratamento sanitário não é incompatível com o art. 32 da Constituição se o tratamento seja destinado não somente a melhorar ou a preservar o estado de saúde de quem será submetido, mas também a preservar o estado de saúde de outros, e de modo que isto não incida negativamente - salvo quando em medida circunstancial e tolerável - sobre o estado de saúde do próprio sujeito (Sentença n⿳0 307 de 1990).

No direito à saúde podem ser compreendidas diversas situações subjetivas, como o direito à integridade psicofísica, o direito à tratamentos sanitários e o direito a um ambiente salubre (ver Sentença $\mathrm{n}^{\circ} 455$ de 1990).

No que diz respeito ao direito à integridade psicofísica, a Corte constitucional o considera como “direito subjetivo" protegido contra qualquer agressão por obra de terceiros (Sentença ${ }^{\circ} 88$ de 1979) e suscetível de uma tutela rissarcitória imediata como “dano biológico”, independentemente de qualquer outra conseqüência danosa

\begin{tabular}{lllllllll}
\hline DiREITOS & FundamentAIS & $\mathcal{E}$ & JUSTIÇA & N & 2 & - & Jan./MAR. & 2008
\end{tabular}


juridicamente determinável: “o dano biológico - tem afirmado a Corte - se refere à integridade dos seus reflexos prejudiciais no que concerne a todas as atividades, situações e relações nas quais a pessoa atribui a si própria na sua vida: não somente, portanto, no que concerne à esfera produtiva, mas também no que concerne à esfera espiritual, cultural, afetiva, social, esportiva e a todos outros âmbitos e modos nos quais o sujeito desenvolve sua personalidade, isto é, a todas 'as atividades realizadoras da pessoa humana"” (Sentenças n ${ }^{\text {os }} 485$ e 356 de 1991).

No que tange, de outra sorte, o direito à tratamentos sanitários, isto é tutelado como direito fundamental no seu "núcleo irrenunciável do direito à saúde, protegido pela Constituição como âmbito inviolável da dignidade humana, o qual impõe em impedir a constituição de situações desprovidas de tutela que possam prejudicar a efetivação do referido direito” (Sentença $n^{\circ} 432$ de 2005). Quanto ao supracitado “núcleo irrenunciável”, que não pode ser restringido nem mesmo por exigências do orçamento público, o direito à tratamentos sanitários é condicionado da atuação que o legislador o atribui mediante contra-balanceamento com outros interesses constitucionalmente protegidos, levados em consideração os recursos estruturais e orçamentários dos quais se dispõe no momento (ver, por exemplo, Sentença ${ }^{\circ} 304$ de 1994). No "núcleo irrenunciável” de tutela da saúde se encontra compreendido, segundo a Corte, “o direito dos cidadãos em limitadas condições econômicas (indigentes segundo a terminologia do art. 32 da Constituição) a que sejam asseguradas curas gratuitas”, o que implica, entre outros, na extensão da previsão de formas de assistência sanitária gratuita em favor dos cidadãos italianos que se encontrem temporariamente no exterior, também por motivos que não sejam apenas de trabalho e de usufruto de bolsas de estudo junto a universidades ou fundações estrangeiras (Sentença $n^{0} 309$ de 1999). Nesta mesma perspectiva, a Corte entendeu que a isenção da participação na manutenção das finanças sanitárias disposta em favor dos aposentados que tenham rendas inferiores a determinados níveis constitui realização do "conteúdo mínimo essencial do direito à tutela da saúde, garantido pelo art. 32 da Constituição, o qual determina que a saúde tenha uma proteção plena, exaustiva e efetiva” (Sentença n ${ }^{\circ} 184$ de 1993).

No seu "núcleo irrenunciável” o direito à saúde deve ser reconhecido também aos estrangeiros, independentemente das "suas condições individuais no que tage às normas que regulam o ingresso e a estadia no Estado, ainda que possa o legislador preveder diversas modalidades de seu exercício”. Mesmo ao estrangeiro presente irregularmente no território do Estado é atribuído, assim, o "direito de usufruir de todas as prestações que resultem inadiáveis e urgentes” (Sentenças n ${ }^{\text {os }} 252$ de 2001 e 432 de 2005).

Na evolução da jurisprudência constitucional, também o direito à salubridade do ambiente se encontra deduzido, como já dito, do direito à saúde. Em tal caso, o art. 32 da Constituição é lido conjuntamente com o art. $9^{\circ} \S 2^{\circ}$, da Constituição, este último que, prescrevendo a tutela da paisagem, requeriria também a proteção do sistema ecológico. Segundo a Corte constitucional, "o ambiente é protegido como elemento determinante da qualidade da vida”. "A sua proteção não busca abstratas finalidades naturalistas ou estéticas, mas exprime a exigência de um habitat natural 
no qual o homem vive e se relaciona e que é necessário à coletividade e, com esta, aos cidadãos, segundo valores largamente sentidos; se impõe, antes de tudo, a partir de preceitos constitucionais (arts. 9 e 32 da Constituição) pelos quais isto se insurge como valor primário e absoluto” (Sentenças n ${ }^{\text {os }} 210$ e 641 de 1987).

O "gozo de um ambiente salubre" parece, em suma, ao mesmo tempo ser interesse da coletividade e direito do indivíduo, enquanto condicionante da saúde, entendida, assim, como situação geral de bem-estar.

\section{O DIREITO AO ESTUDO}

Enfim, no que diz respeito ao "direito ao estudo" (ou “direito à instrução”) deve ser ressaltado que com tal expressão se faz referência a diversas situações jurídicas subjetivas, como o direito de instrução (art. 33 da Constituição), e o direito de ser instruído (art. 34 da Constituição). Sob o primeiro perfil, ganha relevo a liberdade de ensino e a liberdade de instituir escolas e institutos de instrução, especificamente tutelados pelo art. 33 da Constituição; sob o segundo perfil, ganha relevo a liberdade de escolha da escola e o direito a receber uma instrução, especificamente tutelados pelo art. 34 da Constituição A liberdade de escolha da escola é "reforçada" pela previsão da obrigatoriedade e gratuidade da instrução básica, desenvolvida ao longo de ao menos oito anos; o direito a receber uma instrução é garantido (tornado efetivo) pela intervenção do Estado que deve predispor "bolsas de estudo, auxílios às famílias e outras providências", atribuindo-as mediante concurso (art. 34, § $4^{\circ}$ ), e de qualquer forma assegurar aos "mais capazes e merecedores, ainda que desprovidos de meios próprios”, a possibilidade de atingir os níveis mais elevados de estudo (art. 34, § $3^{\circ}$ ).

Como foi precisado pela Corte constitucional (Sentença $n^{\circ} 215$ de 1987), o art. 34, $\S 1^{\circ}$, da Constituição, estatuindo que “a escola é aberta a todos”, e com isto reconhecendo em geral a instrução como direito de todos os cidadãos, "põe um princípio no qual a basilar garantia dos direitos invioláveis do homem 'nas formações sociais onde se desenvolve a sua personalidade garantida pelo art. $2^{\circ}$ da Constituição encontra expressão em referência àquela formação social que é a comunidade escolar. $\mathrm{O}$ art. $2^{\circ}$, deste modo, se conecta e se integra com outra norma, também fundamental, contida no art. $3^{\circ}, \S 2^{\circ}$, que requer a superação das disparidades de situações, seja econômicas ou sociais, suscetíveis de obstaculizar o pleno desenvolvimento das pessoas dos cidadãos”. À luz destes princípios fundamentais, as sucessivas disposições contidas no art. 34 torna "evidente o significado de garantir o direito à instrução, não obstante cada possível obstáculo que de fato impeça o pleno desenvolvimento da pessoa”. A Corte, na já referida Sentença nº 215 de 1987, concernente ao direito à freqüência escolar dos indivíduos portadores de deficiências, tentou definir que se no art. 34 "o enfoque é essencialmente posto sobre obstáculos de ordem econômica", isto, porém, não significa que a aplicação do princípio segundo o qual "a escola é aberta a todos" possa encontrar "limites em obstáculos de outra ordem, cuja remoção é postulada em geral como tarefa da República nas disposições dos arts. $2^{\circ}$ e $3^{\circ}$, $\S 2^{\circ}$ : sustentar isto significaria ignorar o fato evidente que o inserimento na escola e a acquisição de uma completa instrução são instrumentos fundamentais para o

\begin{tabular}{lllllllll}
\hline DiREITOS & FundAMENTAIS & $\varepsilon$ & JUSTIÇA & $\mathrm{N}$ & 2 & - & JAN./MAR. & 2008
\end{tabular}


'pleno desenvolvimento da pessoa humana' que tais disposições colocam como meta a ser atingida”.

Também desta última passagem emerge a vinculação entre o objetivo de remover as desigualdades de fato, estabelecido pelo art. $3^{\circ}, \S 2^{\circ}$, da Constituição e o efetivo gozo dos direitos sociais, o qual deve ser garantido através de adequada legislação. E emerge, paralelamente, a filosofia que fundamenta a jurisprudência constitucional em tema de direitos sociais, que penso, conclusivamente, possa se resumir com a leitura de uma passagem contida em uma outra importante decisão em tema de direito à habitação: “criar as condições mínimas de um Estado social, colaborar para se garantir ao maior número possível de cidadãos um fundamental direito social (...), contribuir para que a vida de cada pessoa reflita cada dia e sob cada aspecto a imagem universal da dignidade humana, são tarefas as quais o Estado não pode abdicar em momento algum.” (Sentença $n^{\circ} 217$ de 1988) 